Proceedings of the 2011 Winter Simulation Conference

S. Jain, R.R. Creasey, J. Himmelspach, K.P. White, and M. Fu, eds.

\title{
COUPLING RELIABILITY AND LOGISTICAL CONSIDERATIONS FOR COMPLEX SYSTEM OF SYSTEMS USING STOCHASTIC PETRI NETS
}

\author{
Vitali Volovoi \\ School of Aerospace Engineering \\ Georgia Institute of Technology \\ Atlanta, VA 30332-0150, USA
}

David K. Peterson

\author{
LMI \\ 2000 Corporate Ridge \\ McLean, VA 22102, USA
}

\begin{abstract}
Sustaining modern, high-technology, system of systems requires a sophisticated coordination of logistics, maintenance policies and operations. Stochastic Petri Nets provide a unique means for simulating the complicated interactions among the individual entities of such systems, and allow leveraging the strengths of both analytical and simulation models against these challenging coordination tasks. The advantages of this modeling approach are demonstrated for a deep-ocean tsunami warning system but are equally applicable to a wide variety of complex system of systems.
\end{abstract}

\section{INTRODUCTION}

Humans have relied upon technology for survival across the millennia. As technology became more sophisticated, so too has this reliance. So deeply rooted is this interrelationship, that the reliability and performance of modern, high-technology, system of systems are almost taken for granted - that is, until something cataclysmic occurs. At that point, we are led to take a step back and ask questions, questions about the world around us and the complex systems that we have developed to better control (or at least cope with) our environment.

An unfortunate illustration of the need for this retrospection are the recent events which so tragically unfolded in Japan. Starting with one of the largest undersea earthquakes in recent history, followed by a very large tsunami wrecking death and destruction across a broad swath of eastern Japan, the long-lasting nuclear energy crisis that arose illustrates how our dependence upon reliable systems has never been greater.

This paper seeks to better understand the reliability of one small, but vital, high-technology system of systems - the Deep-ocean Assessment and Reporting of Tsunamis (DART ${ }^{\circledR}$ ) system operated by the National Oceanic and Atmospheric Administration (NOAA). To better understand and model the DART system we will employ a system of systems framework.

\section{BACKGROUND}

\subsection{Systems}

For the purposes of this paper, we view a system as a "set of objects together with relationships between the objects and between their attributes connected ... to each other and to their environment in such a manner as to form an entity or whole. (Schoderbek et al. 1980)" Taking this basic definition a step further, a system of systems is "a collection of task-oriented or dedicated systems that pool their resources and capabilities together to obtain a new, more complex, 'meta-system' which offers more functionality and performance than simply the sum of the constituent systems. (Popper et al. 2004)" Interestingly, 
Popper goes on to note "Currently, systems of systems is a critical research discipline for which frames of reference, thought processes, quantitative analysis, tools, and design methods are incomplete."

One aspect of the system of systems framework which is incomplete is the ability to link the overall system's reliability to the logistics infrastructure's performance which supports the system. Blanchard (1981) expands upon the importance of considering logistics, saying "The elements of a system include all equipment, related facilities, material, software, data, services, and personnel required for its operation and support ... in its intended operational environment, throughout its planned life cycle." To that end, this paper demonstrates how an analytically-based logistics optimization model may be coupled with a Monte Carlo reliability and maintainability simulation to gain richer and deeper insights into the reliability of a system of systems.

\subsection{The DART II System of Systems}

The system of systems under consideration in this paper is the DART system operated by NOAA. "Originally developed by NOAA, as part of the U.S. National Tsunami Hazard Mitigation Program ... the DART ${ }^{\circledR}$ Project was an effort to maintain and improve the capability for the early detection and real-time reporting of tsunamis in the open ocean. (NDBC 2011a)" Since 2008, the National Data Buoy Center (NDBC) has operated 39 DART II buoys, primarily around the Pacific rim and along the U.S. eastern seaboard. A DART II system (Figure 1) "consists of two physical components: a tsunameter on the ocean floor and a surface buoy with satellite telecommunications capability. The DART II systems have bidirectional communication links and are thus able to send and receive data from the Tsunami Warning Center and others via the Internet." (Meinig 2005)

The bottom pressure recorder (BPR) collects temperature and pressure data which are converted to an estimated sea-surface height which is collected every 15 minutes while the system is operating in standard mode reporting. (NDBC 2011) Using this data, the "Tsunami Detection Algorithm works by first estimating the amplitudes of the pressure fluctuations within the tsunami frequency band, and then testing these amplitudes against a threshold value .... If the amplitudes exceed the threshold, the tsunameter goes into Event Mode to provide detailed information about the tsunami." (Meinig 2005) Once the BPR enters the event mode, " 15 -second values are transmitted during the initial few minutes, followed by 1minute averages. Event mode messages also contain the time of the initial occurrence of the event." (NDBC 2011a)

Figure 2 is a graph from the DART II buoy nearest the Japanese coastline (450 nautical miles NE of Tokyo, Japan). The red vertical lines indicate the BPR capturing the earthquake's initial shockwave at 5:49 GMT (approximately 3 minutes after the actual earthquake). The green vertical lines indicate the east-bound tsunami wave reaching the buoy (approximately 33 minutes after the earthquake) as the wave crosses the Pacific Ocean.

Unfortunately, because of the relative distances involved as the tsunami wave propagated from the earthquake epicenter, people on the eastern seaboard of Japan had to rely on other warning systems (with a corresponding minimal warning time leading to the ultimate tragedy). Nonetheless, the DART II system clearly worked and did provide warnings to other coastal locations around the Pacific Rim, illustrating the value of such a complex, highly-reliable system.

\subsection{Reliability Modeling}

As Blanchard (1981) notes, reliability is "the probability that a system or product will perform in a satisfactory manner for a given period of time when used under specified operating conditions." For example, the DART II system reliability and data return goal is $80 \%$. (Meinig 2005) In this paper we are using Stochastic Petri Nets (SPN) to model the DART II system of systems and its operating environment. SPN structures are state-space based, so the dynamics of a system can be fully captured. However, unlike 


\section{Volovoi and Peterson}

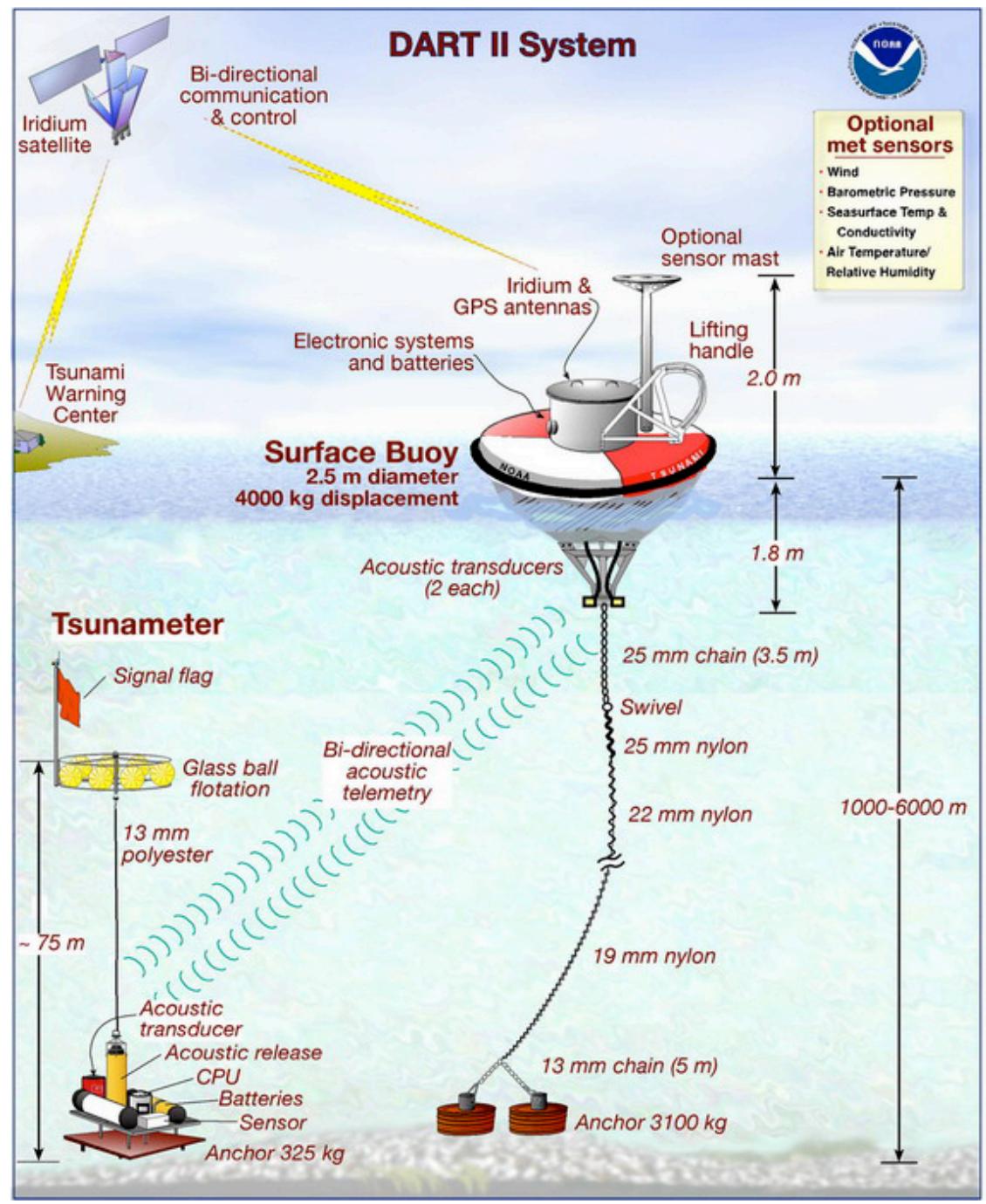

Figure 2: The DART II System - A System of Systems (Source: NOAA Center for Tsunami Research, 2011)

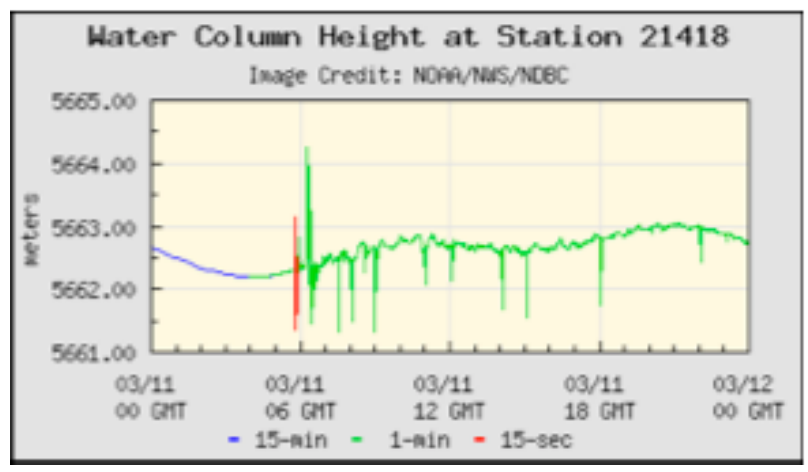

Figure 3: Sea-Surface Height, DART II Buoy Station 21418, March 2011 (Source: NDBC, 2011b) 


\section{Volovoi and Peterson}

Markov chains, where each state represents the system as a whole, in SPN the states of individual components are described, and the state of the system inferred from the states of its components. This "local" view facilitates modeling system aging and often mitigates the state-explosion problem as well. Solutions to SPN can be obtained either by converting the problem to a Markov chain (in the case of systems with constant transition rates) or via Monte Carlo simulation.

SPN models a system in terms of its static (structural) and dynamic (entities) components. In SPN, entities are represented as tokens and places represent the possible states of those entities. (Volovoi 2004) The places that tokens occupy define a particular state of the system, and tokens move between places, simulating changes in the system state. Transitions between places are described by rules for token movements, and transitions only fire when they are enabled (i.e., if certain conditions are satisfied).

SPN models offer distinct advantages for reliability and maintainability (R\&M) modeling. They provide a visual means for dynamic changes in system configuration (i.e., moving tokens). They can model concurrent events and a token can have associated with it continuous counters, which allow keeping track of the token's age. Representing aging effects is a natural extension of colored Petri nets (labels can change discretely upon a token's transition or continuously if a token stays at the same place). In terms of modeling disadvantages, given that SPN models are graphical in nature, they are subject to visualization limits when trying to model complex systems. In addition, their apparent simplicity belies the degree of sophistication required on the part of the R\&M modeler when portraying complex models with multiple interrelationships (e.g., modeling a system of systems).

\subsection{Logistical Modeling}

A key component of a system achieving its design reliability is adequate logistical support. For example, managers are often required to estimate the spare parts needed to sustain a system or a network of specialized equipment (e.g., the DART II system). Such systems are typically composed of many different yet essential components (structural elements, sensors, communications, electronics, power sources, etc.). When those components fail, they must be replaced or repaired with spare parts before the system can resume operations.

The Aircraft Sustainability Model ${ }^{\circledR}(\mathrm{ASM} \otimes)$ sparing model $^{1}$ is a system-oriented approach to spares management, which was designed to answer a fundamental inventory management question: What mix of spare parts is required to keep the system at some desired level of operational availability for a specific scenario? (Kline 2001) The ASM sparing model employs a systems approach that combines probability theory and mathematical modeling to produce an optimal sparing solution. This means a solution in which no other mix of spares can provide greater, system-wide availability for the same cost, or, conversely, the same system availability for less cost (within the scope of the model assumptions and data). In fact, the systems approach, as implemented in the ASM, does not produce merely one solution, but an entire range of feasible sparing solutions over a series of possible inventory budgets.

An important aspect of the ASM sparing model's systems approach is the extension of the usual measures of inventory performance to measures that more directly relate to a particular system. For inventory performance, that measure is the number of backorders or unfilled demands for spare parts. Although backorders can exist and be measured at any location in the supply system, the most important place to measure them is with the end user at the operating storage site. However, the ASM explicitly considers the effect of backorders on the system. To some extent, this depends on the system's complexity, how dispersed the sites are, what policy and procedures exist for cannibalization, what subsystems have redundancy, as well as many other factors that must be taken into account. From these item-level expected backorder projections, the ASM derives their probable effect upon the system's availability.

Using the requirements computation capability of the ASM sparing model, the user enters a target (cost or availability) and the model calculates the optimal spares mix required to meet that target. From this recommended spares mix and system availability target, a corresponding fill rate and logistics delay time (the time from when the need for a repair part was identified until the part was delivered to the maintenance technician) may be estimated. 


\subsection{Model Roles}

In this paper, we develop a method to apply spares optimization to complex networks of high reliability, high redundancy, and high availability equipment. The results of previous research efforts indicate that using the SPN@ Monte Carlo simulation in conjunction with the ASM sparing model can more accurately represent operational availability in systems with complex configurations (such as a system of systems, which may also incorporate redundancy, multi-phased operational mission profiles, and a variety of scheduled and unscheduled maintenance practices).

Reliability models can represent complex redundancies, degraded operations as well as operational or non-operational systems, but they do not optimize spares in terms of minimizing mass, volume or cost. The ASM, with its analytical optimization, rapidly provides a solution equivalent to finding the lowestresource spares mix from millions of simulation trials, but can only model a limited range of redundancy structures. Our goal is to develop an iterative process using SPN@ and the ASM, in tandem, applying the strengths of each model. Together, they provide a more accurate and robust performance measure of the total system (e.g., availability or mission success) which also results in a spares mix that is better balanced across the disparate systems.

\subsection{Model Scenario}

The initial DART II system of systems modeling scenario that we developed required specifying a number of characteristics and assumptions, including:

- Several stations are engaged in detecting the wave

- For modeling purposes, the stations are arranged in order of their proximity to the event source

- If a station is operational, the event signal is sent

- If a station is down, an event signal is not sent. If a spare part is available, the replacement part is installed and the station is repaired (after a maintenance cruise to the buoy location)

- Statistics are collected on the delay of the tsunami warning response

- The initial research question is:

- Probabilistically assess how quickly the tsunami warning system responds to an event.

\subsection{Model Parameterization}

Given the above modeling scenario, the following model parameters (Table 1) were developed from NDBC statistics of the 11 Mar 2011 Japanese earthquake and subsequent tsunami (Table 2). (NDBC 2011b) These event parameters were supplemented by DART II system parameters as described in Meinig (2005). 
Table 1: Model Parameters

\begin{tabular}{|c|c|c|c|c|}
\hline $\mathrm{N}$ & Transition Description & Type & Values & Comments \\
\hline 1 & Tsunami initiation & Fixed/Uniform & varies & Controls the timing of Tsunami \\
\hline 2 & Tsunami traveling time to first station & Lognormal & $37 \mathrm{~min}$ & $\begin{array}{l}\text { First station } 21418 \text { - mean value } 37 \\
\text { minutes; standard deviation } 0.02\end{array}$ \\
\hline 3 & $\begin{array}{l}\text { Tsunami travel between first and } \\
\text { second }\end{array}$ & Lognormal & $44 \mathrm{~min}$ & $\begin{array}{l}\text { The difference in Tsunami arrival time } \\
\text { between the first and the second closest } \\
\text { stations (21413) - mean value is } 44 \text { min; } \\
\text { standard deviation } 0.02\end{array}$ \\
\hline $4,6,8$ & Time to process the signal & Lognormal & $8 \mathrm{~min}$ & 8 minutes; standard deviation 0.1 \\
\hline 5 & $\begin{array}{l}\text { Tsunami travel between second and } \\
\text { third }\end{array}$ & Lognormal & $13 \mathrm{~min}$ & $\begin{array}{l}\text { The difference in Tsunami arrival time } \\
\text { between the second and the third closest } \\
\text { stations - mean value } 13 \text { min; standard } \\
\text { deviation } 0.02\end{array}$ \\
\hline 7 & $\begin{array}{l}\text { Tsunami travel time between the last } \\
\text { station and the cost }\end{array}$ & Lognormal & 8 hours & $\begin{array}{l}\text { Varies depending on the coast (note that } \\
\text { Japan cost was reached in a matter of an } \\
\text { hour) }\end{array}$ \\
\hline $9,10,11$ & Failures for each station & Exp & $1.00 \mathrm{E}-03$ & $\begin{array}{l}\text { All failures are combined for now, failure } \\
\text { rate is based on the available statistics on } \\
\text { availability. MTTF } 1000 \text { days }\end{array}$ \\
\hline $12,13,14$ & Repairs of each station & Lognormal & 1 day & 1 day - when the boat arrives \\
\hline 15 & Clock for starting the boat trip & Fixed & 365 days & Clock indicating the beginning of a new year \\
\hline 27 & $\begin{array}{l}\text { Delay of the boat trip in reference to } \\
\text { the beginning of the year }\end{array}$ & Lognormal & 90 days & $\begin{array}{l}\text { Boat gets there in Spring (so } 90 \text { days from } \\
\text { the beginning of the year). Standard } \\
\text { deviaion } 0.1\end{array}$ \\
\hline \begin{tabular}{|l|}
$24,25,26$ \\
29,31 \\
33,37 \\
\end{tabular} & $\begin{array}{l}\text { Service boats travel time between } \\
\text { the stations (and return to the port) } \\
\text { without repair }\end{array}$ & Lognormal & 7 days & Mean 7 days, standard deviation 0.1 \\
\hline $\begin{array}{l}17,18,20, \\
22 \\
\end{array}$ & $\begin{array}{l}\text { Service boats travel time between } \\
\text { the stations (and return to the port) } \\
\text { with repair }\end{array}$ & Lognormal & 8 days & Mean 8 days, standard deviation 0.1 . \\
\hline 19,2 & Odds & Exp & vary & $\begin{array}{l}\text { Fast exponential distribution is chosen to } \\
\text { compete with transtions } 30,32,34\end{array}$ \\
\hline $30,32,34$ & Odds complementary to $19,21,23$ & Exp & vary & \\
\hline $\begin{array}{l}16,28, \\
36,38\end{array}$ & Immediate transition & Fixed & Small & Small fixed value (value is not important) \\
\hline
\end{tabular}

Table 2: Developing Mileage and Wave Timing Estimates

\begin{tabular}{|c|c|c|}
\hline GMT & LOCATION DESCRIPTION & $\begin{array}{c}\text { DISTANCE FROM } \\
\text { EPICENTER (MILES) }\end{array}$ \\
\hline $5: 46$ & EARTHQUATE EPICENTER & 0 \\
\hline $6: 19$ & DART II STATION 21418 & 333 \\
\hline $7: 03$ & DART II STATION 21413 & 626 \\
\hline $7: 16$ & DART II STATION 21419 & 817 \\
\hline
\end{tabular}

\section{DISCUSSION}

\subsection{The SPN@Buoy Model}

Figure 3 depicts the top portion of an SPN model that represents the tsunami wave propagation from the source of the earthquake and the subsequent generation of a tsunami warning. In SPN's symbology, the small colored circles (tokens) represent relevant entities of the system (e.g., the tsunami, a warning signal, etc). The larger circles are places and represent possible states of these entities (e.g., a buoy station). Tokens move between these places, simulating changes in the system state, and the combination of all the tokens' locations (so-called marking) uniquely characterizes the modeled system. The blue rectangles are timed transitions which describe the roles for tokens moving between places. Tokens are "fired" from one place to another via transitions (once certain conditions are satisfied). The black lines ending in solid black circles are "enablers." That is, as long as a token is in the enabler's place of origination, the transi- 
tion where it terminates is enabled. However, once the place of its origination is empty of tokens, the transition is disabled and that portion of the model is deactivated (e.g., a station is disabled).

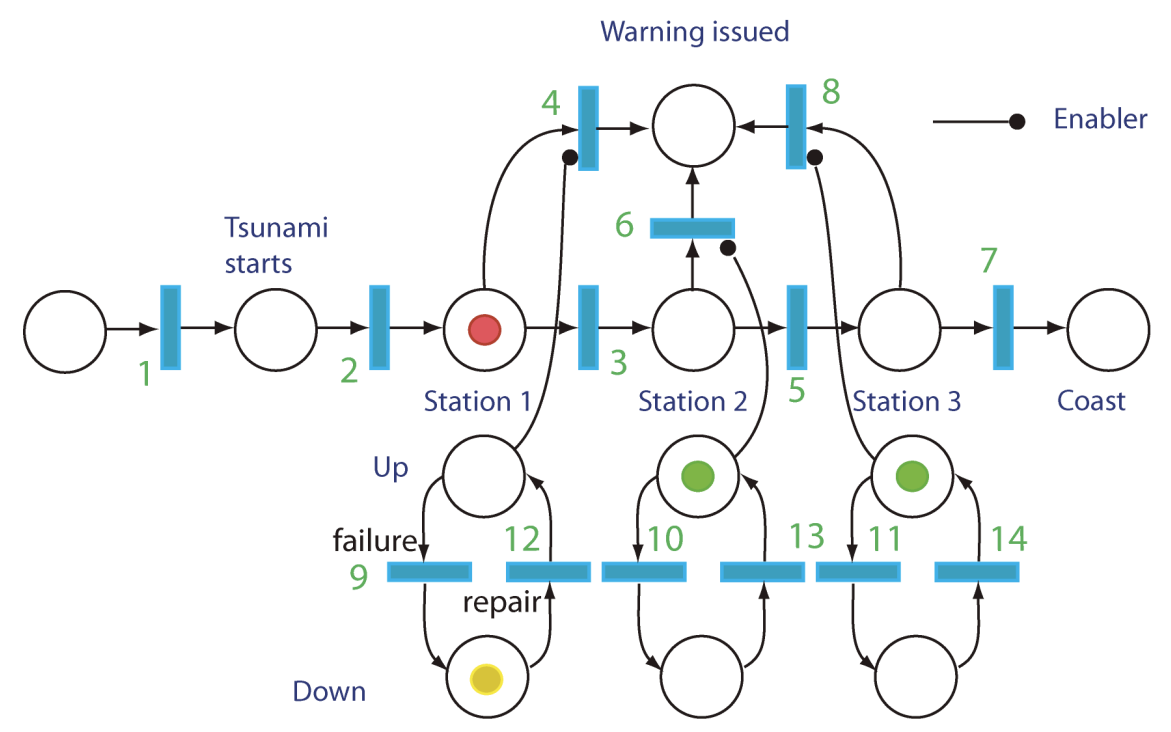

Figure 3: Top Portion of SPN Model: Wave Propagation and Warning

The tsunami is initiated with an earthquake which corresponds to the red token moving to the place "Tsunami starts." The red token moves horizontally from the left to the right reaching Station 1 first. If the station is operational, a corresponding token occupies the "Up" place (i.e., the green tokens), which enables transition number 4, so that a Tsunami warning is generated after an appropriate delay (which represents signal transmission and processing). This is achieved by specifying an enabler (an arc that originates in the place "Up" and terminates with a solid circle at transition 4. In the considered version of SPN, enablers provide a succinct mechanism of describing a coupling between two different portions of the system (and the corresponding token movements). Enablers require a token to be present in the originating place in order for the terminating transition to be enabled. If the station is not operational (and the corresponding token is in a "Down" place (the yellow token), then no warning is issued until the wave reaches the next station. This process is repeated until the first operational station is reached by the wave (represented by the red token reaching Station 2).

The failure and repair processes for an individual station are coupled in the simulation, but here are depicted separately for the sake of clarity (Figure 4). In the depicted simple scenario, station repairs occur when the maintenance boat (represented by a blue token) reaches the station. Similarly to the toplevel model, enablers are used to represent the coupling behavior.

Figure 5 depicts a model that corresponds to a more realistic scenario with logistics considerations taken into account. As the boat arrives at Station 3, and this station is down, then transitions 23 and 34 are enabled. The speed of those transitions is selected based on the fill rate (that is, the chances that the boat has the spare parts needed to repair the station - corresponding to transition 23 and the complementary chances given to transition 34). If transition 34 fires, the color of the boat token changes (the corresponding integer is increased by one). If the station is operational, the boat token is fired through transition 26 instead. Similar events occur at the other stations. If the starting color of the boat was 0 , then after it visited all three stations the boat token's color will indicate the number of unfilled repairs. If that number is greater than zero, then transition 35 fires indicating the need for the boat to return (otherwise transition 36 fires). Finally, transitions 17 and 24 are invoked for the colors that are larger than zero (that is for the boat on its second trip), and the token's color is restored to zero. 


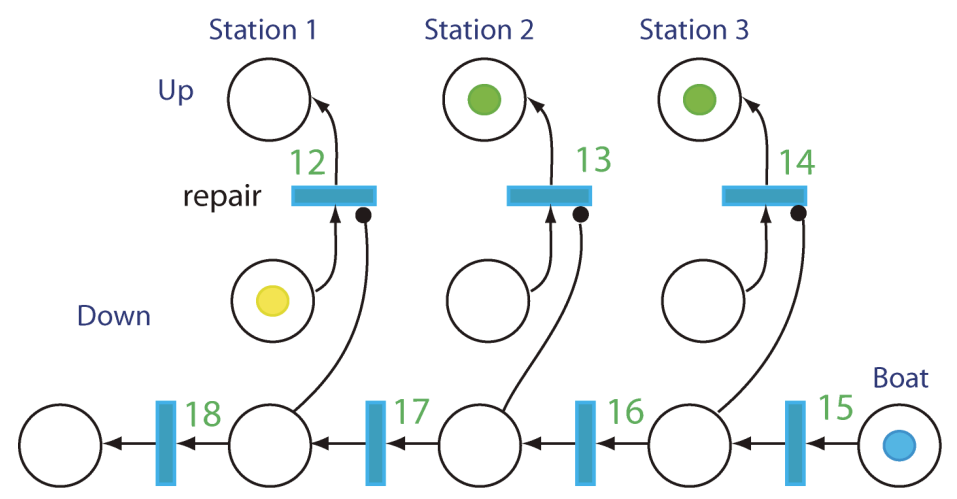

Figure 4: Simple Logistics Portion of the SPN model

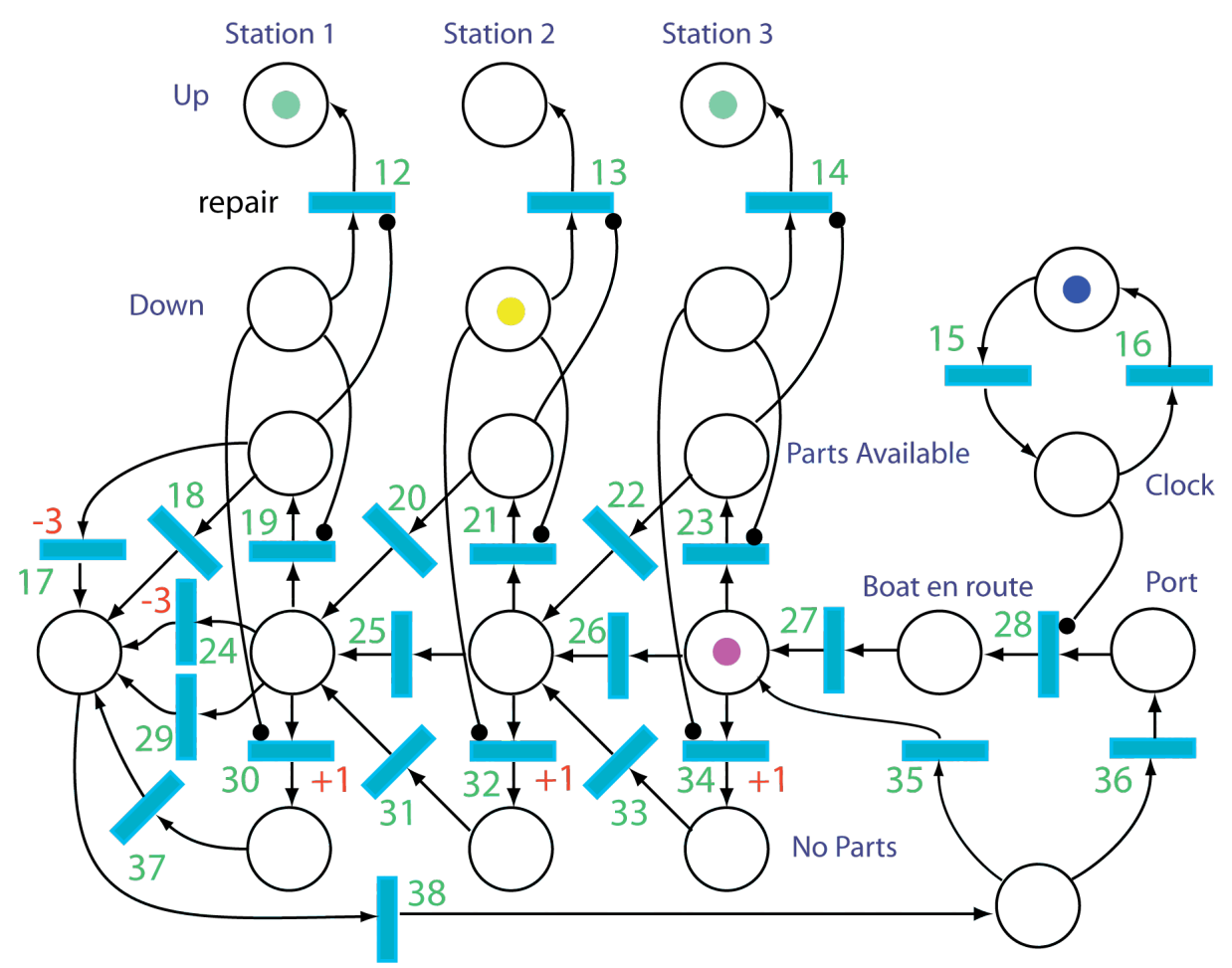

Figure 5: Repair Model Including Logistics

\subsection{Initial Results}

The ASM sparing model requires four types of input data. For system configuration data, Figure 1 was used to define the first indenture surface and sub-surface components of the DART II buoy system (e.g., the transducers, batteries, antennas, etc.) modeled. Unfortunately, component-level reliability data was unavailable, however, the surface and subsurface components have a design maintenance interval of approximately 2 and 4 years (respectively) (Meinig 2005). So, illustrative MTBFs were created for the components, ranging from 1.5 to 3 years, with electronic components being assigned relatively longer MTBFs than structural components. Similarly, while the purchase cost of each component was not available, a DART II buoy's overall cost was given as $\$ 250,000$ (Kong 2002). Thus, illustrative component- 


\section{Volovoi and Peterson}

level costs were developed ranging from $\$ 500$ (for simpler items such as batteries) to $\$ 25,000$ (for the electronic and sensor systems). Finally, illustrative logistics times were developed. A 1 year order and ship time was assumed, along with component repair times and purchase lead times ranging between 1 to 12 months (proportionate to component complexity). The ASM results are summarized in Table 3.

Table 3: ASM Sparing Model Results

\begin{tabular}{|c|c|c|c|c|}
\hline Input Ao & Output Ao & Buy Cost & Fill Rate & LDT \\
\hline 75 & 75.3 & $\$ 508,000$ & $93.6 \%$ & 146.96 \\
\hline 80 & 80.3 & $\$ 535,000$ & $94.7 \%$ & 138.10 \\
\hline 85 & 87.3 & $\$ 585,000$ & $96.4 \%$ & 115.75 \\
\hline 90 & 91.4 & $\$ 627,000$ & $97.5 \%$ & 111.96 \\
\hline 95 & 95.6 & $\$ 694,000$ & $98.6 \%$ & 73.94 \\
\hline
\end{tabular}

Multiple SPN@ simulations were run to find individual station availability, as a function of time (Figures 6, 7, 8) for the fill rates and logistics delay times (LDT) from three ASM runs (for targeted availability $75 \%, 85 \%$, and $95 \%$ ). The simulation starts on January 1,2010 and runs for two years. While the time-averaged availability is about $84 \%$ (NOAA's target), before the repair crew's visit the availability can be significantly lower (at the time of the earthquake it is about $72 \%$ ). One can observe that as the targeted availability increases the second "bump" in the availability curve (the supplementary repair cruise) vanishes. Note also a slight time displacement for each station's availability curve due to the particular order in which the repair crew visits individual stations.

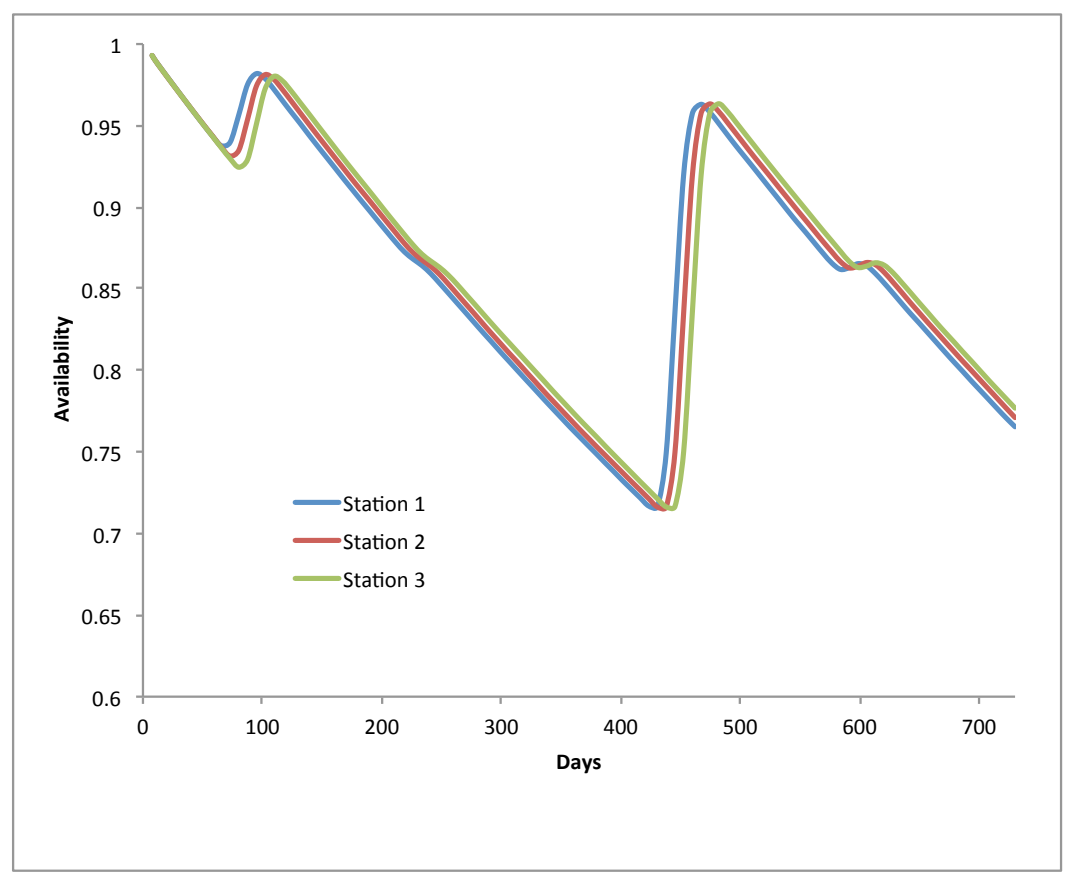

Figure 6: Availability of Individual Stations as a Function of Time. Parameters correspond to ASM case with targeted $75 \%$. 


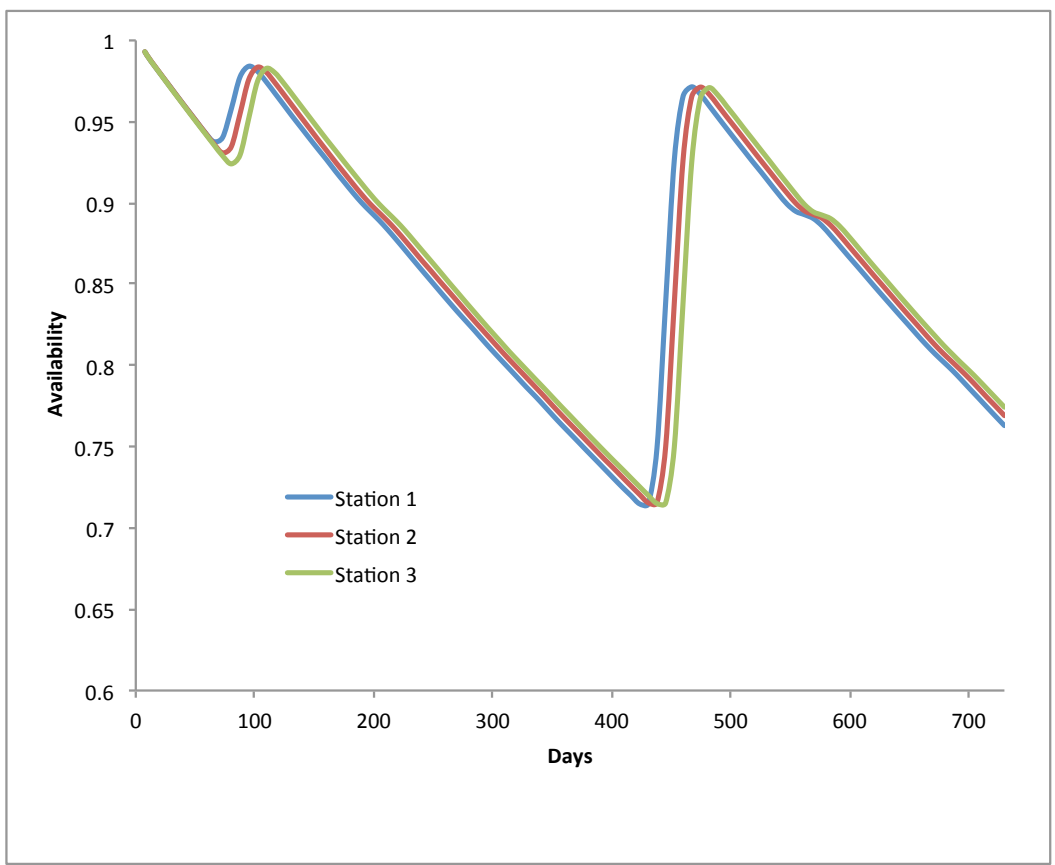

Figure 7: Availability of Individual Stations as a Function of Time. Parameters correspond to ASM case with targeted $85 \%$.

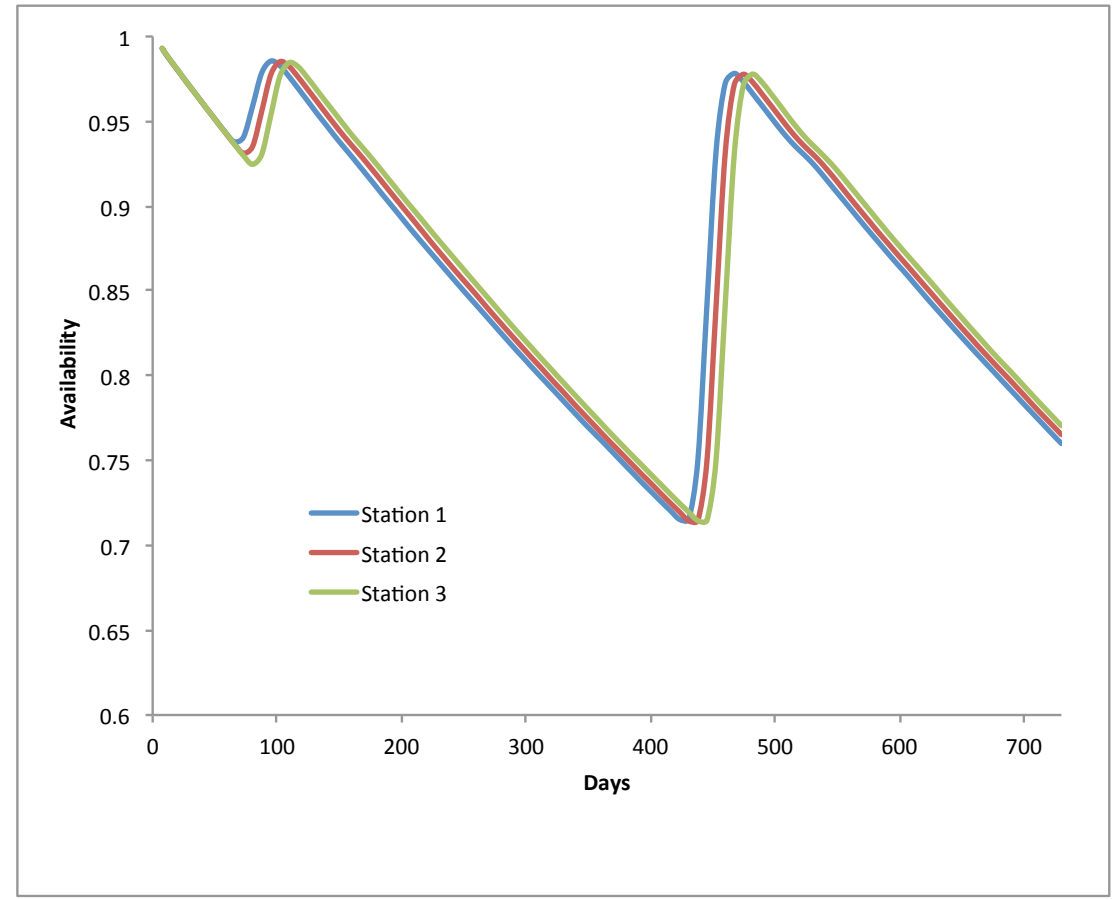

Figure 8: Availability of Individual Stations as a Function of Time. Parameters correspond to ASM case with targeted $95 \%$. 
Figure 9 depicts the cumulative probability function of the system generating a tsunami warning (each step represents the warning generated by a respective station). Within the chart's precision, logistics delay does not affect the system's performance for the considered date.

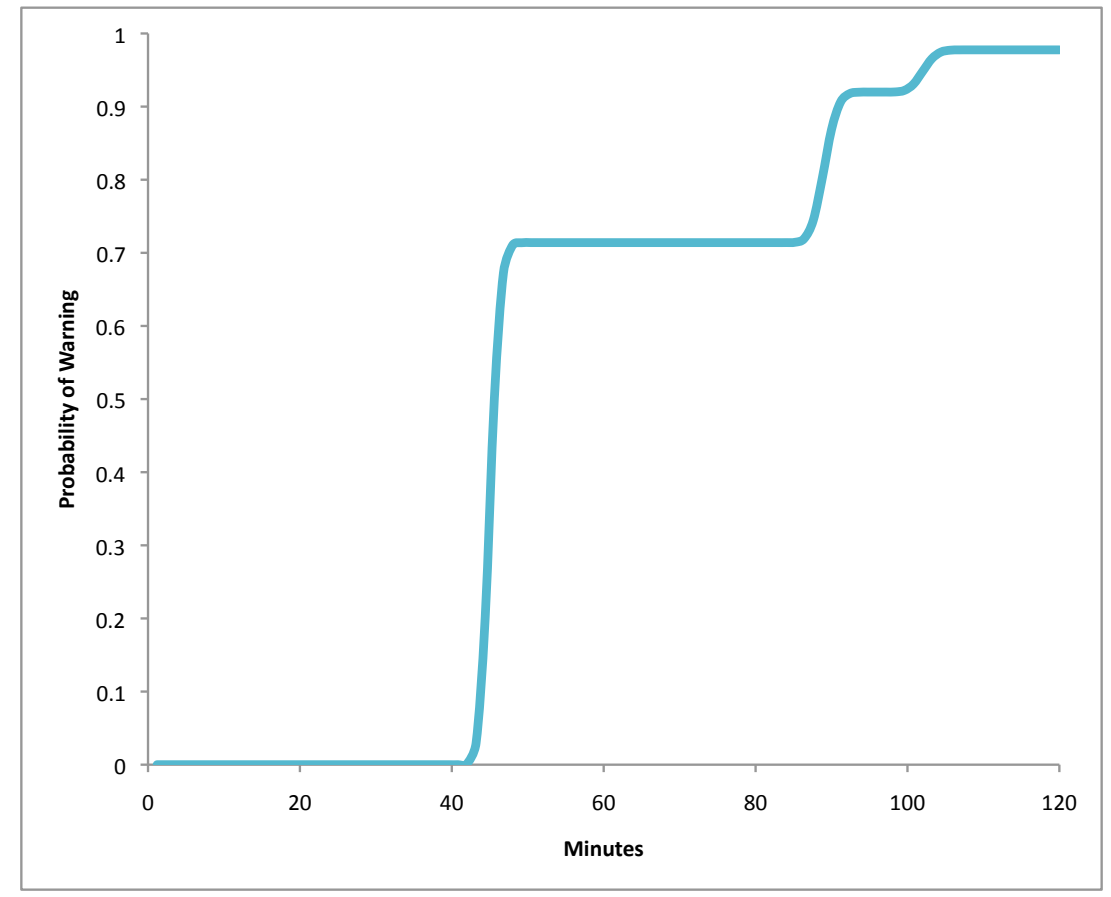

Figure 5: Probability of Warning Generated as a Function of Time (minutes after the earthquake)

\section{SUMMARY}

The initial results above show the potential benefits available from modeling a system of systems using a combination of simulation and analytical models. The examples show the feasibility of modeling a complex, highly reliable system, thus providing a means to relate system sustainment resourcing to overall system performance. Once all of the DART II system and its support network are modeled, we anticipate providing national and international governmental agencies with significant analytical capabilities to evaluate their resourcing of the tsunami warning system.

For the near term, these initial results are strictly intended to be illustrative of how quantifiable benefit projections may be generated by coupling analytical and simulation models. We will continue to refine our models and approach as we learn more about the DART II system and its performance. In the virtual simulation environment enabled by SPN, we will provide decision makers a means to efficiently evaluate any number of resourcing and funding alternatives for any desired level of tsunami warning system reliability.

While our model of the DART II system and its support infrastructure remains under development, this initial research still provides several generalizable insights:

- The value of system of systems modeling - a common platform for depicting the dynamic behavior of a system of systems is described. This approach allows for hierarchically constructing models, thus keeping the complexity of individual models tractable.

- A framework to achieve final objective - along with the intermediate results (such as the time-dependent availability of individual stations), the success of achieving final objectives (e.g., issuing timely tsunami warnings) can be evaluated quantitatively using a combination of modeling approaches. 
- SPN provides a modeling environment ideally suited to the compact representation of system of systems.

- Managerial insights for evaluating resource requirements vs. system performance/reliability using this approach, level-field trade-offs can be conducted to develop an optimal path to improve the likelihood of achieving a desired final objective.

\section{REFERENCES}

Blanchard, Benjamin S. 1981. Logistics Engineering and Management. 2nd ed. Englewood Cliffs, NJ: Prentice-Hall, Inc.

Kline, R. C., et al. 2001. "User's Manual for the Aircraft Sustainability Models, Version 7.0.” LMI Report ASM-UM7.0, Logistics Management Institute, McLean, VA.

Kong, L. 2002. "DART Buoys Provide Real-Time Reporting of Tsunamis." Tsunami Newsletter, XXXIV:1-2,7-8. Accessed 15 July 2011. http://itic.iocunesco.org/images/docs/Apr2002_Vol_XXXIV_No.2.pdf.

Meinig, C., et al. 2005. Real-Time Deep-Ocean Tsunami Measuring, Monitoring, and Reporting System: The NOAA DART II Description and Disclosure. Accessed 28 Feb 2011. http://www.ndbc.noaa.gov/dart/dart_ii_description_6_4_05.pdf.

National Data Buoy Center (NDBC). 2011a. Deep-ocean Assessment and Reporting of Tsunamis (DART®) Description. Accessed 29 Mar 2011. http://www.ndbc.noaa.gov/dart/dart.shtml,.

National Data Buoy Center (NDBC). 2011b. Station 21418 - 450 NM NE of Tokyo, Japan. Accessed 12 Mar 2011. http://www.ndbc.noaa.gov/station_page.php?station=21418.

NOAA Center for Tsunami Research. 2011. DART II System. Accessed 18 Feb 2011. http://nctr.pmel.noaa.gov/Dart/Jpg/DART_II_metric-page.jpg.

Popper, S., et al. 2004. System-of-Systems Symposium: Report on a Summer Conversation, July 21-22, 2004. Accessed 17 Feb 2011. http://en.wikipedia.org/wiki/System_of_systems.

Schoderbek, C. G., et al. 1980. Management Systems: Conceptual Considerations. Revised edition. Dallas: Business Publications, Inc.

Volovoi, V.V. 2004. "Modeling of System Reliability Using Petri Nets with Aging Tokens," Reliability Engineering and System Safety 84:149-161.

\section{END NOTE}

1. Aircraft Sustainability Model and ASM are registered trademarks of Logistics Management Institute.

\section{AUTHOR BIOGRAPHIES}

VITALI VOLOVOI, an Assistant Professor in the School of Aerospace Engineering, has over 80 journal and conference publications. He earned his Ph.D. in Aerospace Engineering from the Georgia Institute of Technology in 1997. His principal fields of expertise are system safety and reliability, risk assessment, analysis and probabilistic design of advanced structures, as well as structural reliability and optimization.

DAVID PETERSON is a senior consultant specializing in readiness-based sparing inventory modeling and its application to Department of Defense logistics support. He earned his Ph.D. in Production and Operations Management from the University of North Carolina in 1987. A retired U. S. Air Force logistician, he received SOLE-The International Society of Logistics' Field Award for Materiel Management in 2009. 